\section{Transpiration and Normalized Difference Vegetation Index Response of Seashore Paspalum to Soil Drying}

\author{
Georgene L. Johnson, Thomas R. Sinclair ${ }^{1}$, and Kevin Kenworthy \\ Agronomy Department, University of Florida, Gainesville, FL 32611-0965
}

Additional index words. drought stress, genotypic variation, Paspalum vaginatum Swartz

\begin{abstract}
A consistent response has been observed among many plant species in their leaf gas exchange as soils are subjected to a drying cycle; except for one case, these studies have not included turfgrass species. The current study reports the change in transpiration rate of six genotypes of seashore paspalum (Paspalum vaginatum Swartz) during soil drying when grown on either an organic soil or sand. On organic soil, the response was consistent with results with other plant species in that there was no decline in transpiration rate until the fraction of transpirable soil water (FTSW) reached the range of 0.25 to 0.31 . The decline in transpiration rate when plants were grown on sand occurred in the FTSW range of 0.10 to 0.17 , which was also consistent with reports for other species when grown on sand. The lower FTSW for the decline in transpiration rate on sand appears to be a result of the greater retention of water in fully wetted sand in pot experiments as compared with field conditions. Because the decline in transpiration occurred at a higher FTSW in 'SeaIsle Supreme', 'Aloha', and 'SeaIsle 1' than in 'SeaIsle 2000', this is an indication that these genotypes are water-conserving and may be better suited to water-deficit conditions. Quality changes in these grasses were monitored daily during the drying cycle by reflectance measurements of their normalized difference vegetation index (NDVI). No change in NDVI was observed for grasses grown on either soil type until the soil had become very dry and transpiration had decreased to low rates.
\end{abstract}

Water use by turfgrass is an issue of increasing concern because nonsaline water resources are becoming more expensive and scarce. A key question is how dry can soil become before it limits physiological activity and growth of grasses? Although it is understood that water deficits in the plant result in loss of cell turgor and wilting, stomata closure, decreased photosynthetic rates, cessation of cell enlargement, and interruption of many metabolic processes (Kramer and Boyer, 1995), these results offer little concrete guidance about overall plant response to soil water content.

An increasing number of studies, primarily with field crops, have shown that there is a close correlation between plant activity and soil water content. Sadras and Milroy (1996) reviewed this literature and found that plant gas exchange, including photosynthesis rate, did not decrease for most situations until the fraction of extractable soil water content had decreased to a range of 0.25 to 0.40 . Variation in the soil water content at which the decline in gas exchange occurred was attributed to soil characteristics and species differences. Although Sadras and Milroy identified no studies with turfgrasses, Miller (2000) has since reported a study with 'Tifdwarf' bermudagrass (Cynodon dactylon L. Pers. $\times C$. transvaalensis Burtt Davy) grown on either U.S. Golf Association specification sand or

Received for publication 24 Nov. 2008. Accepted for publication 4 Jan. 2009.

${ }^{1}$ To whom reprint requests should be addressed; e-mail trsincl@ifas.ufl.edu. fine sand. The results showed the same twosegment response observed in other plant species. The average fraction of transpirable soil water (FTSW) for two soils and two experiments at which bermudagrass water loss rate began to decrease was 0.30 .

This current study was undertaken to extend studies on relative rate of water loss of turfgrasses in response to drying soils to six cultivars of seashore paspalum (Paspalum vaginatum Swartz). Seashore paspalum is a highly salt-tolerant, warm-season species (Duncan, 1998) that is adapted to tropical and subtropical regions of the world (Trenholm and Unruh, 2002). Interest and use of seashore paspalum on golf courses has increased in the last 10 years as a result of the availability of several new cultivars with high turf quality. Tolerance to saline environments has become the definitive trait for this species; however, it is also known to grow well in a wide variety of soil textures and $\mathrm{pH}$ levels and to have a comparatively lower nitrogen requirement (Duncan, 1998; Trenholm and Unruh, 2002).

Possible genotypic differences in response to drying soil could be critical in developing turf with greater tolerance to drying soil. Huang et al. (1997) ranked the drought resistance of four seashore paspalum genotypes in comparison with three other warm-season species. They reported that variation existed among the tested seashore paspalum genotypes and that breeding for related characteristics could further improve drought resistance. However, breeding would be facilitated by identifying the specific physiological trait that contributes to variation in drought tolerance. A high volumetric soil water content at which transpiration rate begins to decrease would be a possible mechanism to conserve soil water and maintain turf quality for a longer time as drought conditions persist. Identification of possible genotypic differences is a critical first step in breeding for enhanced performance with soil drying.

To fully understand the influence of turfgrass response to soil drying, it may be necessary to compare the response of grasses to drying soil when grown on divergent soil types. Sand is used to construct green surfaces on golf courses, whereas other turf areas typically use native soils (sand, loam, or clay). In $2002, \approx 73 \%$ of the turf grown in Florida was grown in a sand-based soil and $23 \%$ grown in muck soils (Haydu et al., 2003). Sinclair et al. (1998) found in their experiments that sandy soils gave a response different from usually observed with most other soils. The soil water content (FTSW) at which plant transpiration rate began to decline was quite low. In their study, the breakpoint for the decline in soybean gas exchange among five sandy soils ranged from 0.11 to 0.18 in FTSW. They concluded that the lower breakpoint for the sandy soils was the result of difficulty in defining the upper drained limit for sandy soils in their pot study. In pot studies, zero potential may exist at the bottom of the pot so that the amount of water held by sand in these pots was greatly exaggerated relative to field situations.

The objective of this study was to compare the relative water loss rates of six cultivars of seashore paspalum as soil was allowed to dry. The experiment was performed using two soils: an organic soil and sand, which are relevant to turf growth in Florida. The data were analyzed to determine the breakpoint at which water loss rate declined relative to well-watered controls. Radiation reflectance data were also recorded in this study with seashore paspalum cultivars as a possible means for monitoring changes in grass quality associated with soil drying.

\section{Materials and Methods}

Transpiration response to drying soil was tested using clonally propagated plugs grown in $15-\mathrm{cm}$ diameter $\times 12.5-\mathrm{cm}$ tall pots in a greenhouse at the University of Florida in Gainesville, FL. Although the size of these pots may have induced some binding of root growth, water extraction with soil drying was found to be unaffected under root-bound conditions for soybean and maize (Zea mays L.) (Ray and Sinclair, 1998). The first set of plugs was planted in sand on 24 July 2006 . A second set of plugs was planted on 18 Oct. 2006 into pots filled with Black Kow ${ }^{\circledR}$ Topsoil (Black Gold Compost Co., Oxford, FL), which is a blend of organic soil collected from peat deposits in Florida. The drainage holes in all pots were filled with Poly-fil (Fairfield Processing Corporation, Danbury, CT) to prevent soil loss from the pots. Pots were filled to within 1 inch from the top with their respective soil media. There were 
10 pots of each soil type for each of the six most prominent seashore paspalum genotypes: 'Aloha', 'SeaIsle Supreme', 'SeaIsle 1', 'SeaIsle 2000', 'Salam', and 'SeaDwarf'. The pots were maintained in a greenhouse under natural daylength by watering daily. Weekly fertilization of all pots was done by applying $42 \mathrm{mg}$ Peters Professional 20-2020 Water Soluble Fertilizer (Scots, Siera Horticultural Products Co., Marysville, OH). The grasses were trimmed three times a week to $2.5 \mathrm{~cm}$. During the dry-down experiment, the average minimum and maximum temperatures in the greenhouse were $23.9 \pm 1.3{ }^{\circ} \mathrm{C}$ and $33.6 \pm 2.9^{\circ} \mathrm{C}$, respectively.

The dry-down experiment for all pots was initiated on 27 June 2007 when the grass completely covered the soil surface in each pot. All pots were trimmed and fully watered in the late afternoon so that water drained freely from each pot. The next morning after the pots were no longer draining, each pot was weighed to obtain the weight for the upper limit of extractable water in each pot. To obtain transpiration rate for a period of $\approx 24 \mathrm{~h}$, the weight of each pot was recorded at $\approx 1400$ HR each day. Four of the 10 pots for each soil type and genotype were identified for maintenance in a well-watered condition. Water was added each day to each wellwatered pot to return its weight to $100 \mathrm{~g}$ less than its initial weight. The $100-\mathrm{g}$ deficit prevented the soil from being water-saturated yet maintained the soil water in the wellwatered range for these control pots. Decrease in the soil water content of the six drying pots of each grass was controlled by rewatering the pots so that the drying cycle extended over at least 2 weeks. On each day, water was added to each of the drying pots if necessary to return pot weight to $\approx 50 \mathrm{~g}$ below the net pot weight on the previous day. As a result of the closed canopy of the grasses preventing evaporation from the soil surface, all the changes in pot weight during the experiment were assumed to result from transpiration. Daily transpiration rate of each pot was calculated by subtracting the pot weight measured on the current day from the combined weight on the previous day of the pot and added water.

The response of each pot to drying on each day was assessed by calculating the ratio between transpiration rate of the drying pot and the mean transpiration rate of the four well-watered pots on each day (Miller, 2000; Sinclair and Ludlow, 1986). This ratio in transpiration rates allowed ambient environmental fluctuations, particularly varying evaporation conditions, to be minimized in the day-to-day comparisons of transpiration rate. Because transpiration rate varied among pots, a second normalization was done so that transpiration rate for each pot was adjusted to a value of 1.0 while the grass was still in the well-watered condition. The transpiration ratios on the first few days of the drying cycle while the pots were still in a well-watered state were used to calculate the normalization value for each pot. The transpiration ratio on each day was divided by the average of the transpiration ratios from the first few days for each pot. Consequently, the average normalized transpiration rate (NTR) for these initial dates was equal to 1.0.

The level of water-deficit achieved in each drying pot on each day was expressed as the FTSW remaining in the pot (Miller, 2000; Sinclair and Ludlow, 1986). In this approach, the total transpirable water was the difference between the initial pot weight and the pot weight recorded when NTR had decreased to a value less than 0.1 . The value of FTSW on each day was calculated as the ratio of the transpirable water remaining in the pot to the total transpirable water of the pot.

The radiation reflectance of the grasses during the drying cycle was monitored by measuring the normalized difference vegetation index (NDVI) using a Field Scout ${ }^{\circledR}$ TCM 500 "NDVI" turf color meter (Spectrum Technologies, Inc., Plainfield, IL) daily for each drying pot. The instrument was placed directly on the turfgrass because it uses an internal light source for the measurement of reflectance. The field of view was $7.6 \mathrm{~cm}$ in diameter. NDVI is calculated as $\left(\mathrm{R}_{\mathrm{NIR}}-\mathrm{R}_{\mathrm{red}}\right)$ / $\left(R_{N I R}+R_{\text {red }}\right)$ where $R_{N I R}$ is the reflectance in an near infrared wavelength $(850 \mathrm{~nm})$ and $R_{\text {red }}$ is the reflectance in the red wavelength (660 $\mathrm{nm}$ ). Bell et al. (2002) reported that NDVI is closely correlated with visual color ratings in tall fescue (Festuca arundinacea Schreb). In bermudagrass, NDVI has been shown to be comparatively more correlated than visual assessment of irrigation status, nitrogen fertilization, and turf quality (Xiong et al., 2007).

The response of NTR and NDVI to FTSW was analyzed using a two-segment linear regression model (Prism, Version 2.01; GraphPad Software, Inc., San Diego, CA). The model for the double linear regression was:

$$
\text { If FTSW } \geq X_{0}, \mathrm{~T}_{\mathrm{r}}=\mathrm{S}_{1}(\mathrm{FTSW})+\mathrm{C} 1
$$

\section{If FTSW $<X_{0}, \mathrm{~T}_{\mathrm{r}}=\mathrm{S}_{2}(\mathrm{FTSW})+\mathrm{C} 2$}

where $X_{0}$ is the breakpoint between the two line segments and $S_{1}$ and $S_{2}$ the slopes of the two regression segments. In the regression, the second line segment is constrained to intersect with the first line segment at $X_{0}$, which is defined as the breakpoint in the response to decreasing FTSW.

\section{Results and Discussion}

The total amount of soil water extracted from the pots in this study was slightly greater from the organic top soil (537 g) as compared with the sand $(461 \mathrm{~g})$. The large amount of water extracted from the sand as compared with the organic soil is surprising considering the relative low extractable soil water usually associated with sands. This result is likely a consequence of a water potential near zero at the beginning of this pot experiment so that the drained upper limit would be much higher than under field conditions in which the zero reference water potential is deeper in the soil. The nature of the water extraction curve of sandy soils means that a small difference in the water potential at the upper level has a large influence on the volumetric amount of water retained in the soil.

There were no differences among the six genotypes in the amount of water extracted from the top soil. On the sand, only the amount of water extracted by 'SeaIsle Supreme' (436 g) and 'SeaIsle 2000' (479 g) was significantly different $(P<0.05)$; all other genotypic comparisons showed no significant difference.

The response of plant water loss on drying soil for these seashore paspalum cultivars was very similar to that observed for many other plant species (Sadras and Milroy, 1996) and Tifdwarf bermudagrass (Miller, 2000). The typical two-segment response to drying soil was observed for all cases in this study. As illustrated by the results of 'Aloha' (Fig. 1), the response of NTR to FTSW for both the organic soil and the sand media was well represented by the two-segment model. The breakpoint in NTR response for 'Aloha' was calculated to be at FTSW of 0.28 for organic soil and 0.16 for sand. The two-segment model described well $\left(r^{2}>0.94\right.$ in all cases $)$ results obtained for all genotypes (Table 1).

The average breakpoint in transpiration rate on drying sand was 0.14 , which is much less than commonly reported but consistent with the breakpoint reported by Sinclair et al. (1998) for soybean grown on sandy soil. The breakpoint they reported for soybean was 0.18 for a sandy soil. The observed low breakpoint on sand is likely a consequence of the large amount of extractable measured in pots resulting from a high estimate for the upper limit of extractable soil water content. As compared with the field, the high estimate for drained upper limit would shift the breakpoint to a lower FTSW in the pot results. The breakpoint for 'SeaIsle 2000' was found to be significantly lower than the breakpoint for 'SeaIsle Supreme', 'Aloha', and 'SeaIsle 1'. The basis for the comparatively low breakpoint
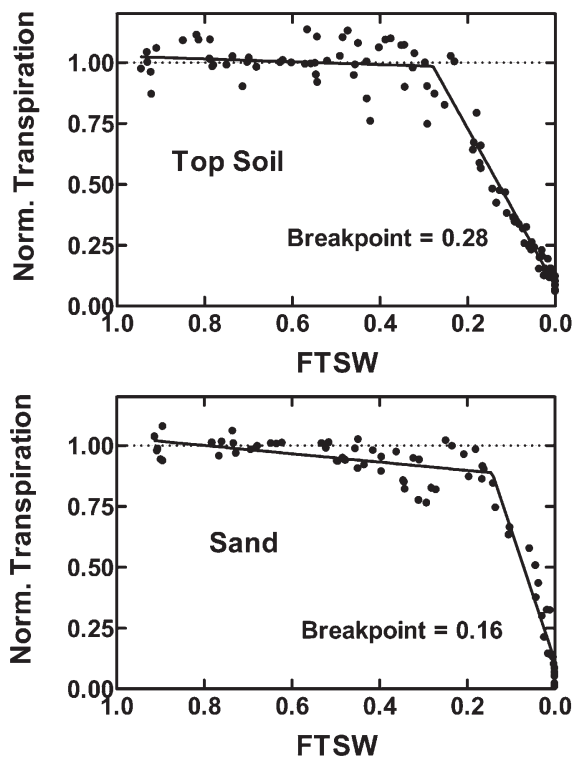

Fig. 1. Normalized transpiration of 'Aloha' plotted as a function of the fraction of transpirable soil water (FTSW) during a drying cycle when grown on organic soil and sand. 
Table 1. Breakpoint of normalized transpiration rate (NTR) calculated for each genotype grown either on organic soil or sand. ${ }^{z}$

\begin{tabular}{lccccccc}
\hline & \multicolumn{3}{c}{ Organic soil } & & \multicolumn{3}{c}{ Sand } \\
\cline { 2 - 3 } Genotype & Breakpoint & $\begin{array}{c}95 \% \text { confidence } \\
\text { interval }\end{array}$ & $r^{2}$ & & Breakpoint & $\begin{array}{c}\text { 95\% confidence } \\
\text { interval }\end{array}$ & $r^{2}$ \\
\hline Salam & 0.248 & 0.041 & 0.972 & & 0.122 & 0.032 & 0.958 \\
SeaIsle Supreme & 0.259 & 0.049 & 0.943 & & 0.171 & 0.028 & 0.961 \\
Sea Dwarf & 0.276 & 0.045 & 0.966 & & 0.148 & 0.034 & 0.962 \\
Aloha & 0.284 & 0.045 & 0.963 & & 0.164 & 0.033 & 0.960 \\
SeaIsle 1 & 0.290 & 0.044 & 0.968 & & 0.150 & 0.032 & 0.944 \\
SeaIsle 2000 & 0.310 & 0.044 & 0.975 & & 0.099 & 0.018 & 0.978 \\
\hline
\end{tabular}

${ }^{\mathrm{z}}$ The breakpoint is defined in terms of the fraction of transpirable soil water (FTSW) at which NTR was found to begin decreasing as the soil dried.

of 'SeaIsle 2000' is not clear. The theoretical analysis of Sinclair (2005) does not indicate any plant trait that would have a dominating impact on the breakpoint.

One possibility to explain the differences in the breakpoint among genotypes may be differences in plant growth whereby a low breakpoint would be associated with slow growth and low water demand. However, based on clipping weights, there was no difference in the growth of 'SeaIsle 2000' as compared with the three genotypes with a higher breakpoint (data not shown). Another possibility is that root length density may have differed among the genotypes. On porous sands particularly, root length density could become important in limiting hydraulic conductivity in the soil at low volumetric water contents. Those plants with greater root length density to shorten the distance for water flux in the soil might sustain high water uptake to lower soil water contents. Therefore, the low breakpoint for 'SeaIsle 2000' might reflect a greater root length density than 'SeaIsle Supreme', 'Aloha', and 'SeaIsle 1'. A greater root length density for 'SeaIsle 2000' would be consistent with the observation that it extracted more water from this sand than

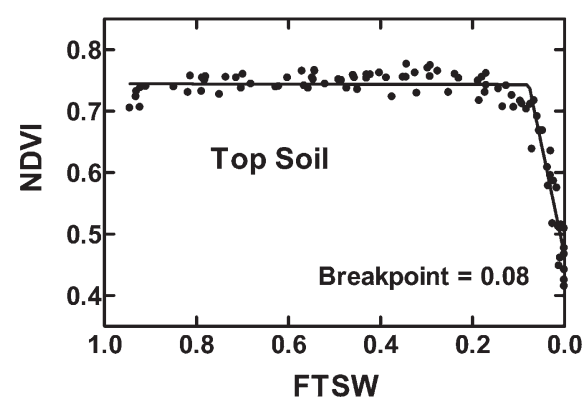

Fig. 2. Normalized difference vegetation index of 'Aloha' plotted as a function of the fraction of transpirable soil water (FTSW) during a drying cycle when grown on organic soil.

Table 2. Breakpoint of normalized difference vegetation index calculated for each genotype grown on organic soil. $^{\mathrm{z}}$

\begin{tabular}{lccc}
\hline Genotype & Breakpoint & 95\% confidence interval & $r^{2}$ \\
\hline Salam & 0.068 & 0.028 & 0.835 \\
SeaIsle Supreme & 0.074 & 0.020 & 0.875 \\
Sea Dwarf & 0.105 & 0.032 & 0.841 \\
Aloha & 0.079 & 0.014 & 0.938 \\
SeaIsle 1 & 0.123 & 0.026 & 0.898 \\
SeaIsle 2000 & 0.052 & 0.022 & 0.758 \\
\hline
\end{tabular}

${ }^{\mathrm{z}}$ The breakpoint is defined in terms of the fraction of transpirable soil water (FTSW) at which normalized transpiration rate was found to begin decreasing as the soil dried. response to soil drying. On the organic soil, there was no significant difference among genotypes in the breakpoint in transpiration rate as the soil dried. A novel finding of this study was that the breakpoint in the NDVI was at a much lower soil water content than the initiation of the decrease in transpiration rate. These results showed that 'SeaIsle 2000', 'Salam', and 'Aloha' expressed a loss in visual quality at comparatively low soil water contents. The results when the plants grown on sand were consistent with previous results showing a very low transpiration breakpoint. The breakpoint results appear to be shifted to low soil water contents as a result of the high estimate for the sand drained upper limit in pot experiments. Nevertheless, 'SeaIsle Supreme', 'Aloha', and 'SeaIsle' had higher transpiration breakpoints than 'SeaIsle 2000' as the sand dried, indicating that these three genotypes are more conservative in their water use and may be better positioned to tolerate periods of water deficit.

\section{Literature Cited}

Bell, G.E., D.L. Martin, S.G. Wiese, D.D. Dobson, M.W. Smith, M.L. Stone, and J.B. Solie. 2002. Vehicle-mounted optical sensing: An objective means for evaluating of turf quality. Crop Sci. 42:197-201.

Duncan, R.R. 1998. Seashore paspalum herbicide management. USGA Green Section Record, p. $17-19$.

Haydu, J.J., L.N. Satterthwaite, and J.L. Cisar. 2003. An economic and agronomic profile of Florida's sod industry in 2003. EDIS Publication FE561. Department of Food and Resource Economics, University of Florida, Gainesville, FL.

Huang, B., R.R. Duncan, and R.N. Carrow. 1997. Drought-resistant mechanisms of seven warmseason turfgrasses under surface soil drying: Shoot response. Crop Sci. 37:1858-1863.

Kramer, P.J. and J.S. Boyer. 1995. Water relations of plants and soils. Academic Press, San Diego, CA.

Miller, G.L. 2000. Physiological response of bermudagrass grown in soil amendments during drought stress. HortScience 35:213-216.

Ray, J.D. and T.R. Sinclair. 1998. The effect of pot size on growth and transpiration of maize and soybean during water deficit stress. J. Expt. Bot. 49:1381-1386

Sadras, V.O. and S.P. Milroy. 1996. Soil-water thresholds for the response of leaf expansion and gas exchange: A review. Field Crops Res. $27: 253-266$

Sinclair, T.R. 2005. Theoretical analysis of soil and plant traits influencing daily plant water flux on drying soils. Agron. J. 97:1148-1152.

Sinclair, T.R., L.C. Hammond, and J. Harrison. 1998. Extractable soil water and transpiration rate of soybean on sandy soils. Agron. J. 90:363-368.

Sinclair, T.R. and M.M. Ludlow. 1986. Influence of soil water supply on the plant water balance of four tropical grain legumes. Aust. J. Plant Physiol. 13:329-341.

Trenholm, L.E. and J.B. Unruh. 2002. Seashore paspalum for Florida lawns. EDIS Publication CIR-1244. Environmental Horticulture Department, University of Florida, Gainesville, FL.

Xiong, X., G.E. Bell, J.B. Solie, M.W. Smith, and B. Martin. 2007. Bermudagrass seasonal responses to nitrogen fertilization and irrigation detected using optical sensing. Crop Sci. 47:1603-1610. 